\title{
Are Mentorship and Training the Key in Provision of Emergency Obstetric and New-Born Care (Em0NC) Services? A Formative Evaluation of Pre and Post in Samburu County, Kenya
}

\author{
Majiwa Fredrick ${ }^{1}$, Mukami Diana1, Kiarie Jackline', Kiilu Colleta1, Maithya Ruth², \\ Gikunda George1, Munyalo Bonnie², Omogi Jarim²* \\ ${ }^{1}$ Amref Health Africa, Nairobi, Kenya \\ ${ }^{2}$ Amref International University, Nairobi, Kenya \\ Email: ^majiwafred@gmail.com
}

How to cite this paper: Fredrick, M., Diana, M., Jackline, K., Colleta, K., Ruth, M., George, G., Bonnie, M. and Jarim, O. (2021) Are Mentorship and Training the Key in Provision of Emergency Obstetric and New-Born Care (EmONC) Services? A Formative Evaluation of Pre and Post in Samburu County, Kenya. Open Journal of Clinical Diagnostics, 11, 100-111.

https://doi.org/10.4236/ojcd.2021.114008

Received: October 19, 2021

Accepted: December 25, 2021

Published: December 28, 2021

Copyright $\odot 2021$ by author(s) and Scientific Research Publishing Inc. This work is licensed under the Creative Commons Attribution International License (CC BY 4.0).

http://creativecommons.org/licenses/by/4.0/ (c) (i) Open Access

\begin{abstract}
Background: In Kenya, the Maternal Mortality Ratio (MMR) is approximated to 362 maternal deaths per 100,000 live births while the stillbirth rate stands at 23 deaths per 100 live births which are far below the target of 147 maternal mortality per 100,000 live births and 12 stillbirths per 100 live births respectively. Progress in addressing preventable maternal and newborn deaths and stillbirths depend on the improvement of the quality of maternal, fetal and newborn care throughout the continuum of care. Objective: To determine the effect of mentorship and training in improving the provision of $\mathrm{Ba}$ sic Emergency Obstetric Newborn Care (BEmONC) and Comprehensive Emergency Obstetric Newborn Care (CeMONC) services among health workers in Samburu County. Methodology: A one-week training intervention was carried among health workers in level three, four and five health facilities by master trainers. Using two tools adopted from MEASURE Evaluation and a structured questionnaire, a total of 54 (before the intervention) and 64 (after the intervention) health workers from 29 health facilities were interviewed. Training effectiveness was assessed by means of questionnaires administered pre- and post-training, by correlating post-training results of health workers, and through participatory observations at the time of on-site supervisory visits, mentorship and monthly meetings. An assessment was conducted to measure the level of confidence of the health workers in performing their duties. Results: Central Samburu had the majority of the health workers both at the pre-intervention (44.4\%) and post-intervention (51.6\%), North Samburu had an extra health worker at post-test while no change in numbers was recorded
\end{abstract}


in East Samburu. A majority of the health workers across the three sub-counties were 31 - 40 years old, with only 2 (3.8\%) aged 51 years and above. Following the interventions, improvements in the practice of BEmONC services were seen across the three sub-counties. There was an increase, at post analysis, in the use of the partograph to monitor labour (from 52\% to $98.1 \%$ ) and managing severe infection in the newborn (from $40.4 \%$ to $60.3 \%$ ). Performing CS improved from $17.3 \%$ to $31 \%$ and the same was also recorded in carrying out blood transfusions. On post-survey, health workers reported the least confidence in performing manual vacuum. Other BEmONC services including active management of $3^{\text {rd }}$ stage labor, use of partograph, manual removal of the placenta, managing maternal sepsis and identifying danger signs in the newborn had a high rate of confidence. Conclusions: This study finds that structured mentorship is an effective strategy to build the capacity of health workers. However, there is a need for further research to monitor and evaluate if such programmes improve clinical outcomes in the long run.

\section{Keywords}

Emergency Obstetric Newborn Care, Health Workers, Training, Mentorship

\section{Introduction}

Globally, thousands of women die annually from complications during the pregnancy, childbirth and postpartum period, with most deaths occurring in developing countries [1].

According to the World Health Organization (WHO), approximately 295,000 women died during and following pregnancy and childbirth in 2017 with $94 \%$ of these deaths occurring in the low resources setting [2].

WHO reports that approximately 810 women die every day from preventable causes related to pregnancy and childbirth. It also adds that neonatal deaths within the first 28 days of birth are associated with the lack of quality care at birth or skilled care and treatment immediately after birth. In addition, women who receive care from professional midwives that have been trained to international standards are $16 \%$ less likely to lose their baby, and $24 \%$ less likely to experience preterm birth [3].

According to the Kenya Demographic and Health Survey (KDHS) 2014, the Maternal Mortality Ratio (MMR) is 362 per 100,000 live births, and the neonatal mortality rate is 23 deaths per 1000 live births. This is far below the target of 147 maternal mortality per 100,000 live births and 12 stillbirths per 1000 live births respectively [4].

Skilled attendance at birth remains low in sub-Saharan Africa [5] with data in Kenya showing that only $61.8 \%$ of deliveries are being attended to by a skilled provider [6]. Studies show that the lack of knowledge on basic diagnosis and 
management of common diseases is often associated with ineffective or harmful healthcare practices [7]. Lack of trained health workers in low- and middle-income countries in addition to the uneven geographical distribution of the few available health workforce pose a formidable challenge in achieving universal healthcare coverage [1]. This implies that there is a need to identify and invest in effective approaches to support health workers post-training to deliver quality client-centered care, a core component of Health Systems Strengthening (HSS) needed to achieve universal health coverage. Studies have shown that mentorship and training programmes play key roles when it comes to improving the quality of care provided [8].

Emergency Obstetric Newborn Care (EmONC) is defined as a set of evidencebased interventions used in preventing and managing obstetric complications [9]. Every birthing woman should have access to these lifesaving interventions also referred to as EmONC signal functions. Although the global Maternal and Newborn Health $(\mathrm{MNH})$ outcomes improved to some extent with the implementation of Millennium Development Goals (MDGs), the agenda has been advanced in the Sustainable Development Goals with an aim to significantly reduce maternal and neonatal deaths by the year 2030. Indeed, one of the targets under SDG 3 is to reduce the global Maternal Mortality Ratio (MMR) to less than 70 per 100,000 live births by the year 2030 [10]. To effect this, there is a need for quality service delivery on Basic Emergency Obstetric and Newborn Care (BEmONC), which evidence has shown can be improved through mentorship and training of health workers. Indeed, having a Skilled Birth Attendant (SBA) for every birth remains the single most critical intervention in reducing maternal and neonatal deaths.

According to the World Health Organization (WHO), most maternal deaths are preventable when healthcare solutions that can be used to either manage or prevent complications are well established. Women need access to antenatal care in pregnancy, skilled care during childbirth, and care and support in the weeks after childbirth [11].

A lot of work and investment in increasing the number of health workers and improving health infrastructure in Africa has been focused on training. However, the expansion of spaces within which health workers can be mentored to improve performance output has been neglected [12].

According to Kenya Health Sector Strategic Plan (KHSSP), inadequate numbers of trained specialists and subspecialists is among the key issues that need to be addressed with an aim of increasing the numbers and capacity of human resources for health [13].

This has been adopted by the national government and the devolved county governments, including Samburu. Though obstetric complications such as postpartum haemorrhage, sepsis, eclampsia, and obstructed labour that can cause maternal death cannot be predicted, a majority can be treated with timely provision of a package of evidence-based interventions known as emergency obstetric 
care (EmOC) [14]. Improving the provision of EmOC in Samburu County remains the cornerstone of Amref Health Africa's maternal and child health strategy. For this reason, Amref Health Africa and the County Government of Samburu initiated Mentoring and Training at Health Facilities to improve the quality of care on EmONC services. EmONC key interventions include:

1) Administer parenteral antibiotics;

2) Administer parenteral oxytocic drugs;

3) Administer parenteral anticonvulsants for pregnancy-induced hypertension;

4) Manual removal of placenta;

5) Removal of retained products of conception (e.g., vacuum aspiration);

6) Assisted vaginal delivery (e.g., vacuum extraction, forceps);

7) Perform basic neonatal resuscitation;

8) Caesarean delivery;

9) Blood transfusion.

Health facilities that perform the first- 7 functions routinely qualify as a basic EmONC facility, while those that perform all the -nine functions routinely qualify as a comprehensive EmONC facility.

This study aimed at assessing the effectiveness of mentorship and training of health workers in the provision of BEmONC services in Samburu County, Kenya.

\section{Methods}

\subsection{Study Area and Design}

Samburu County is within the northern parts of the Great Rift Valley in Kenya, covering an area of $21,022 \mathrm{Km}^{2}$ with $80 \%$ of the residents being pastoralists. Administratively, the County is divided into three sub-counties: Samburu Central, Samburu East and Samburu North. The county has a total of 95 health facilities including the county referral hospital at level 5, sub-county hospitals at level 4, nursing homes and health centres at level 3 and dispensaries at level 2. The average distance from a household to a health facility is $25 \mathrm{kms}$, which is way above the national recommended distance of $4 \mathrm{kms}$.

This was a formative evaluation that employed a pre and post intervention design, following the implementation of a maternal and child health project across the three sub counties. The formative evaluation study design was selected because it was more relevant in providing evidence for intervention effectiveness [14]. The study utilized quantitative methods to collect data from the health workers.

\section{Intervention}

Health workers in Level 3 (Health Centres, maternity and nursing homes), Level 4 (Sub-County Hospitals) and Level 5 (County Referral Hospitals) were mentored and trained by master trainers, drawn from Samburu County oriented on the tools and the mentorship approach before they carried out field work. In order to encourage ownership and consistency of the intervention, the same mas- 
ter trainers were involved in earlier training of the heath workers on BEmONC. A master trainer was a nurse/midwife who had undergone a Training of Trainers (TOT) course in BEmONC and certified competent. A two-phase mentoring and training programme was developed as a continuous quality improvement measure for EmONC services in three sub-counties in Samburu County Kenya.

The mentorship approach adopted involved the identification of competency gaps followed by onsite mentorship by way of On-the-Job-Training (OJT) and coaching with the help of job aids.

The activity took one week in June 2018 and the follow up was done after 4 months in November 2018.

\subsection{Sample Size and Sampling Procedure}

A total of 54 health workers were interviewed before the intervention while 64 were interviewed after the intervention. In addition, 29 health facilities were randomly selected from a total of 52 health facilities that were part of the project.

\subsection{Data Collection Procedure}

The evaluation tools were adapted from the MEASURE evaluation Toolkit [15]. Two specific tools were extracted from the toolkit and named as Facility Evaluation Tool and Provider Survey Tool. An Action Plan Template was also developed.

Baseline data on demographic information of the health workers, whether they offer BEmONC services and their level confidence in offering BEmONC services were collected before the intervention in June 2018 for one week.

The mentorship approach adopted involved the identification of health workers' competency gaps followed by onsite mentorship by way of On-the-Job-Training (OJT) and coaching with the help of job aids. Some of the interventions carried out included: development and adaptation of the mentorship tools, orientation of master trainers on the mentorship approach, on site mentorship using job aids, and action planning.

\subsubsection{Development \& Adaptation of the Mentorship Tools}

Job aids for BEmONC service provision were adapted from existing guidelines, particularly the Ministry of Health (MOH) National guidelines for Quality Obstetric and New-born Care. Key job aids were selected and printed for the exercise.

\subsubsection{Orientation of Master Trainers on the Mentorship Approach}

Master trainers drawn from the county were oriented on the tools and the mentorship approach before the field work. It is worth noting that the same master trainers were involved in earlier training of the health workers on BEmONC.

\subsubsection{On Site Mentorship Using Job Aids}

Mentors identified competency gaps on BEmONC signal functions and provided on site mentorship on coaching. Job aids were used to emphasize key issues. Ad- 
ditionally, each facility was given copies of laminated job aids and guided on where to strategically display them. The job aids were to act as a quick reference during service provision. The set of Job aids shared included for active management of third stage of labour, management of Post-Partum Haemorrhage (PPH), Kangaroo Mother Care, Manual Removal of the placenta and hand washing. Others included administration of magnesium sulphate, neonatal resuscitation, warm chain, vacuum extraction and PPH drug management.

\subsubsection{Action Planning}

Each facility was guided on how to develop an action plan to help address competency gaps as well as address any challenges in the facility. The participants were advised to identify actions they could implement within a specified period of time. Copies of the action plans were made, allowing the facility to retain one for accountability. The action plans provided an important reference point for the post mentorship activity.

\subsection{Data Analysis}

Statistical analysis was performed using STATA version 15 (StataCorp, College Station, TX, USA). Exploratory data analysis involved checking the data for outliers and errors using frequency using distribution tables and graphs. Frequency distribution tables and graphs were also used to visualize categorical variables, while means and standard deviations were used in analyzing continuous data before and after the intervention.

\subsection{Ethical Approval}

Ethical approval was sought from Amref Ethics and Scientific Review Committee (ESRC P484/2018) and County Health Management Committee in Samburu. The questionnaire was filled through face-to-face interaction with the health workers after briefly explaining the study objective and getting their consent to participate in the study. Prior to implementation, the questionnaire was pretested and changes made accordingly.

\section{Results}

\subsection{Demographic Characteristics of the Respondents}

At pre-test, a total of 54 health workers were interviewed comprising of Central 24 (44.4\%), East 15 (27.8\%) and North 15 (27.8\%); while at post-test, Central had 33 (51.6\%), North 16 (25\%) with East remaining at 15 (23.4\%) in East Samburu.

Generally, 33 (51.6\%) female health workers were reached during the Post Test. Registered nurses remained the majority 43 (67.2\%) while health workers who had diploma were $53(82.8 \%)$. A majority of the health workers across the three Sub-Counties were 31 - 40 years old, while only $2(3.7 \%)$ were aged 51 years and above. Similarly, the Post Test Survey reported only 4 (6.3\%) health workers aged more than 50 years as shown in Table 1 . 
Table 1. Demographic characteristics of the health workers.

\begin{tabular}{|c|c|c|c|c|c|c|c|c|}
\hline \multirow[t]{2}{*}{ Variable } & \multicolumn{2}{|c|}{ All } & \multicolumn{2}{|c|}{ Central } & \multicolumn{2}{|c|}{ East } & \multicolumn{2}{|c|}{ North } \\
\hline & $\begin{array}{l}\text { Pre-test } \\
\mathrm{N}(\%)\end{array}$ & $\begin{array}{c}\text { Post-test } \\
\text { N (\%) }\end{array}$ & $\begin{array}{c}\text { Pre-test } \\
\text { n (\%) }\end{array}$ & $\begin{array}{c}\text { Post-test } \\
\text { n (\%) }\end{array}$ & $\begin{array}{c}\text { Pre-test } \\
\text { n (\%) }\end{array}$ & $\begin{array}{c}\text { Post-test } \\
\text { n (\%) }\end{array}$ & $\begin{array}{c}\text { Pre-test } \\
\text { n (\%) }\end{array}$ & $\begin{array}{c}\text { Post-test } \\
\text { n (\%) }\end{array}$ \\
\hline \multicolumn{9}{|l|}{ Gender } \\
\hline Male & $29(53.7)$ & $31(48.4)$ & $11(45.8)$ & $13(39.4)$ & $8(53.3)$ & $8(53.3)$ & $10(66.7)$ & $10(62.5)$ \\
\hline Female & $25(46.3)$ & $33(51.6)$ & $13(54.2)$ & $20(60.6)$ & $7(46,7)$ & $7(46.7)$ & $5(33.3)$ & $6(37.5)$ \\
\hline \multicolumn{9}{|l|}{ Professional cadre } \\
\hline Registered nurse & $36(67.9)$ & $43(67.2)$ & $17(73.9)$ & $20(60.6)$ & $11(73.3)$ & $13(86.7)$ & $8(53.3)$ & $10(62.5)$ \\
\hline Enrolled nurse & $9(17)$ & $10(15.6)$ & $4(17.4)$ & $4(12.1)$ & $2(13.3)$ & $2(13.3)$ & $3(20)$ & $4(25)$ \\
\hline Registered clinical officer & $6(11.3)$ & $8(12.5)$ & $2(8.7)$ & $7(21.2)$ & $1(6.7)$ & 0 & $3(20)$ & $1(6.3)$ \\
\hline Others (MO, Paediatrician) & $2(3.8)$ & $3(4.8)$ & 0 & $1(6.1)$ & $1(6.7)$ & 0 & $1(6.7)$ & $1(6.2)$ \\
\hline \multicolumn{9}{|l|}{ Education level } \\
\hline Certificate & $6(11.1)$ & $10(15.6)$ & $2(8.3)$ & $4(12.1)$ & $1(6.7)$ & $2(13.3)$ & $3(20)$ & $4(25)$ \\
\hline Diploma & $43(79.6)$ & $53(82.8)$ & $20(83.3)$ & $28(84.8)$ & $13(86.7)$ & $13(86.7)$ & $10(66.7)$ & $12(75)$ \\
\hline Degree & $5(9.3)$ & $1(1.6)$ & $2(8.3)$ & $1(3.1)$ & $1(6.7)$ & 0 & $2(13.3)$ & 0 \\
\hline \multicolumn{9}{|l|}{ Age } \\
\hline$<30$ years & $9(17)$ & $11(17.2)$ & $2(8.7)$ & $6(18.2)$ & $3(20)$ & $3(20)$ & $4(26.7)$ & $2(12.5)$ \\
\hline 31 - 40 years & $27(50.9)$ & $26(40.6)$ & $14(60.9)$ & $15(45.5)$ & $8(53.3)$ & $5(33.3)$ & $5(33.3)$ & $6(37.5)$ \\
\hline 41 - 50 years & $15(28.3)$ & $23(35.9)$ & $7(30.4)$ & $9(27.3)$ & $3(20)$ & $7(46.7)$ & $5(33.3)$ & $7(43.8)$ \\
\hline$>50$ years & $2(3.8)$ & $4(6.3)$ & 0 & $3(9.1)$ & $1(6.7)$ & 0 & $1(6.7)$ & $1(6.2)$ \\
\hline
\end{tabular}

\subsection{Practice of EmONC Services}

The study sought to determine the practice of EmONC services by the health workers in their respective health facilities. There was an increase, at post analysis, of almost all the EmONC services with the major one being on the health workers using the partograph to monitor labour (52\% to $98.1 \%$ ), managing severe infection in the new-born ( $40.4 \%$ to $60.3 \%)$. Though only three health facilities offer CEmONC related services in Samburu County, there seems to have been improvement on the two services namely performing Caesarean Section (CS) and assisting in blood transfusion. Performing CS improved from $17.3 \%$ to $31 \%$ and the same was also recorded in carrying out blood transfusion as shown in Figure 1.

\subsection{Confidence in Performing BEmONC Services}

Using a Likert scale of 5 levels with 1 denoting low confidence and 5 denoting high confidence, the highest change (22\%) was on the use of partograph. On the other hand, performing neonatal resuscitation and managing severe infection in the new-born recorded a 5\% change. Providing active management of $3^{\text {rd }}$ Stage of labour recorded a $4 \%$ increase while performing vacuum extraction at birth and performing manual vacuum aspiration had a $3 \%$ change each. Identifying 
danger signs in the new born had a $2 \%$ change while no change was recorded in performing manual removal of placenta, managing maternal sepsis and administering parenteral anticonvulsants as shown in Table 2.

The evaluation also assessed implementation of the action plans developed at the beginning of the exercise in which a total of 29 facilities had implemented up to $80 \%$ of the actions.

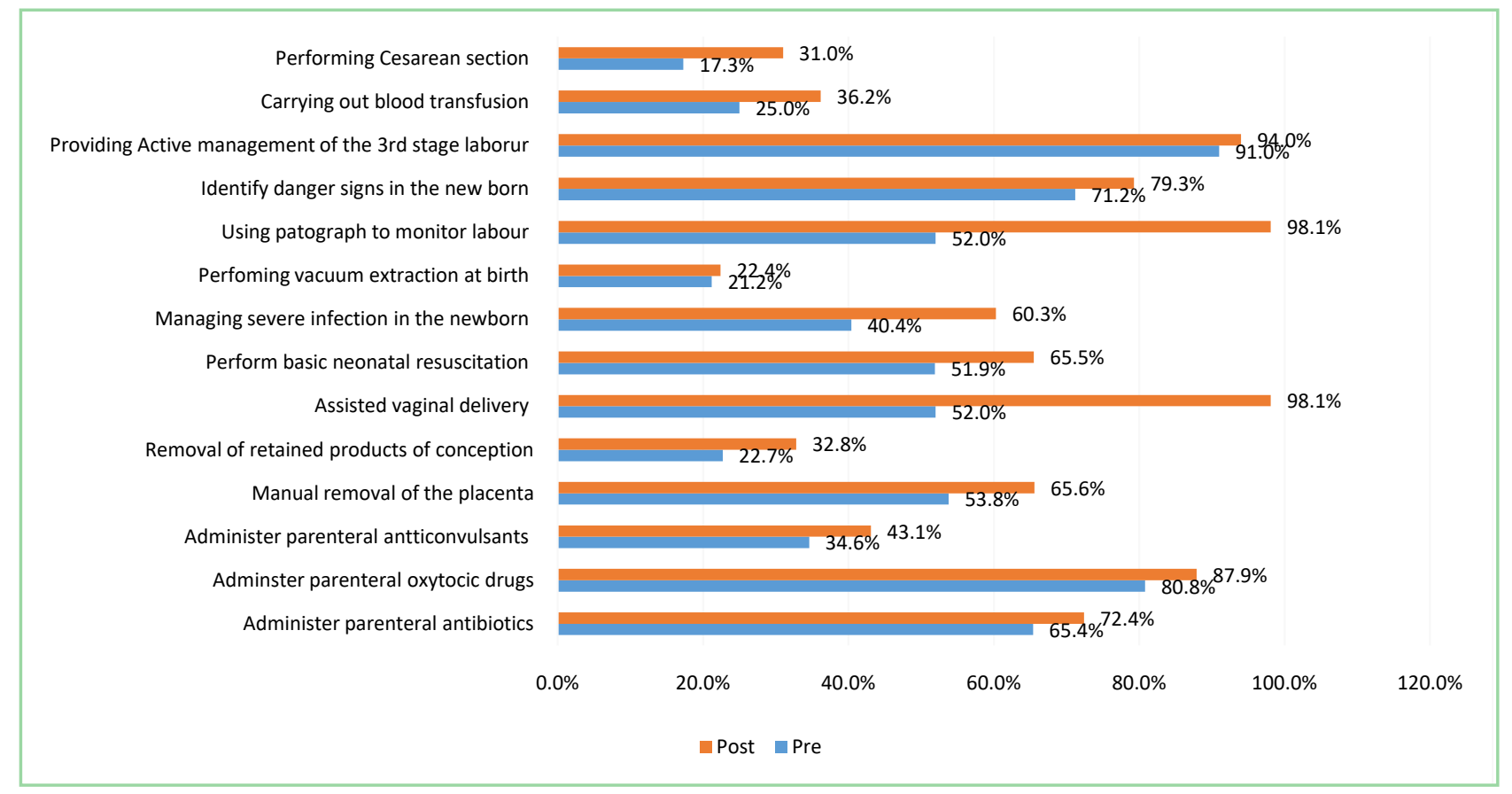

Figure 1. Pre and post analysis of EmONC functions performed by the health workers.

Table 2. Confidence levels in carrying out EmONC services.

\begin{tabular}{|c|c|c|c|c|}
\hline EmONC services & Pre-test (A) & Post-test (B) & Change: B-A & $\%$ \\
\hline Providing active management of 3 rd stage of labour & 4.7 & 4.9 & 0.2 & $4 \%$ \\
\hline Using partograph & 3.7 & 4.5 & 0.8 & $22 \%$ \\
\hline Performing manual removal of the placenta & 4.7 & 4.7 & 0 & $0 \%$ \\
\hline Managing maternal sepsis & 4.7 & 4.7 & 0 & $0 \%$ \\
\hline Identifying danger signs in the newborn & 4.7 & 4.8 & 0.1 & $2 \%$ \\
\hline Administering uterononic drugs & 4.6 & 4.8 & 0.2 & $4 \%$ \\
\hline Performing neonatal resuscitation & 4.4 & 4.6 & 0.2 & $5 \%$ \\
\hline Managing severe infection in the newborn & 4.3 & 4.5 & 0.2 & $5 \%$ \\
\hline Administering parenteral anticonvulsants & 4.2 & 4.2 & 0 & $0 \%$ \\
\hline Performing manual vacuum aspiration & 3.8 & 3.9 & 0.1 & $3 \%$ \\
\hline Performing vacuum extraction at birth & 3.3 & 3.4 & 0.1 & $3 \%$ \\
\hline Carrying out blood transfusion & 3.1 & 4.3 & 1.2 & $39 \%$ \\
\hline Performing caesarean section & 2.6 & 3.4 & 0.8 & $31 \%$ \\
\hline
\end{tabular}




\section{Discussion}

The increase in capacity to offer EmoNC services could be attributed to the fact that mentorship increases competency in handling obstetric conditions [16]. Furthermore, a combination of both academic and corporate practice capacity building provided better ground for fostering knowledge and skills [17]. Teaching, training, and resulting career development opportunities are important factors to improve standards of care [1].

Mentorship fosters a supportive learning relationship between an individual who is willing and able to share knowledge, experience and wisdom with another individual who is ready and willing to benefit from this exchange, to enrich their professional journey [18]. During the last 2 decades attention has focused on improving patient care and the need for health organizations to maintain the public's trust by ensuring that nurses and other health professionals demonstrate competence in their work [19]. This has included skills to deliver quality maternal and newborn health services.

Management of various services in emergency obstetric improved after the mentorship period. This is consistent to a systematic review study in which before and after study, reported a change in clinical practice 3 months after training in effective perinatal care with a 4-fold increase in the use of the partograph [20]. The study found that provision of CeMONC services increased. This could have been attributed to the fact that involving the health workers in the therapeutic team fostered ownership of the actions [21]. The results are similar to a before and after study that reported an increase (from $43 \%$ to a $56 \%$ ) in availability and performance of EmOC signal functions at healthcare facilities designated to provide Basic or Comprehensive EmOC [19]. Increase in provision of EmONC services was also found in a retrospective study evaluating the impact of PAC training for 434 midwives and 53 medical doctors (trained separately) in Ghana which showed an increase in after training of the availability of post abortion care (PAC) with both doctors and midwives providing this service unlike before when it was only offered by doctors [22].

There was an increase in confidence on the use of partograph, active management of 3rd stage labour, use of partograph, manual removal of the placenta, managing maternal sepsis and identifying danger signs in the newborn. The provision of extra training and following with mentorship outside the normal classroom setting provided this environment [23] [24]. According to [25] mentoring increases both mentor and mentee confidence and skills, ability to give feedback, and identification of their own learning and developmental needs. In another study done to increase first year students nurses with peer mentoring, the first year undergraduate mentioned someone to talk to who would not be intimidating, a fellow student with whom they could share their experiences-both good and bad, someone they could ask anything without feeling stupid and someone who would be a listening ear and who would not judge their lack of knowledge as what they thought would improve their confidence and their experience [26]. Mentorship 
has also been found to boost the confidence of Transitioning Registered Nurses (TRN) in Emergency Departments (ED) [27].

\section{Conclusion}

This study is consistent with other research and recommendations that depict mentorship as an effective strategy to foster competency of clinical staff in the management of obstetric conditions. There is room for the adaptation of mentorship to various settings. In addition, addressing broader barriers to the health system will improve the mentorship programme of health care workers. There is, however, a need for further research to monitor and evaluate whether such programmes improve clinical outcomes in the long run.

\section{Authors' Contributions}

DM: conceived the study design, interpretation, analysis, and made drafting of the paper. JK: conceived the study design and methods and made drafting parts of the paper. FM: conceived the study design, interpretation, analysis, and critical review of the document. RM, BM: interpretation and critical review; and JO: conceived the study design and methods, interpretation and analysis and critical review of the document. All authors read and approved the final manuscript.

\section{Acknowledgements}

This project was funded by M-Pesa Foundation.

We take this opportunity to extend our gratitude to the County Government of Samburu and all the staff of the health facilities for taking part in this project and for the time they took to respond to the survey questionnaires and provided us with valuable information.

\section{Conflicts of Interest}

The authors declare no conflicts of interest regarding the publication of this paper.

\section{References}

[1] Jaeger, F.N., Bechir, M., Harouna, M., Moto, D.D. and Utzinger, J. (2018) Challenges and Opportunities for Healthcare Workers in a Rural District of Chad. BMC Health Services Research, 18, Article No. 7. https://doi.org/10.1186/s12913-017-2799-6

[2] WHO (World Health Organization) (2019) Trends in Maternal Mortality. 2000 to 2017: Estimates by WHO, UNICEF, UNFPA, World Bank Group and the United Nations Population Division. World Health Organization Geneva.

[3] World Health Organization (2020) Maternal Health. https://www.who.int/health-topics/maternal-health\#tab=tab 1

[4] Kenya National Bureau of Statistics (KNBS) and ICF Macro (2015) Kenya Demographic and Health Survey 2014-15. KNBS and ICF Macro, Nairobi.

[5] Lang'at, E., Mwanri, L. and Temmerman, M. (2019) Effects of Implementing Free Maternity Service Policy in Kenya: An Interrupted Time Series Analysis. BMC Health 
Services Research, 19, 1-10. https://doi.org/10.1186/s12913-019-4462-X

[6] Manzi, A., Magge, H., Hedt-Gauthier, B., Michaelis, A., Cyamatare, F.R., Nyirazinyoye, L., Hirschhom, L.R. and Ntaganira, J. (2014) Clinical Mentorship to Improve Pediatric Quality of Care at the Health Centers in Rural Rwanda: A Qualitative Study of Perceptions and Acceptability of Health Care Workers. BMC Health Services Research, 14, Article No. 275. https://doi.org/10.1186/1472-6963-14-275

[7] Rowe, A., De Savigny, D., Lanata, C. and Victora, C. (2005) How Can We Achieve and Maintain High-Quality Performance of Health Workers in Low-Resource Settings? The Lancet, 366, 1026-1035. https://doi.org/10.1016/S0140-6736(05)67028-6

[8] Sikder, S.S., Labrique, A.B., Ali, H., Hanif, A.A., Klemm, R.D., Mehra, S., West, K.P. and Christian, P. (2015) Availability of Emergency Obstetric Care (EmOC) among Public and Private Health Facilities in Rural Northwest Bangladesh. BMC Public Health, 15, Article No. 36. https://doi.org/10.1186/s12889-015-1405-2

[9] UNICEF, WHO, World Bank and UN-DESA Population Division (2019). Levels and Trends in Child Mortality Report 2019. Estimates Developed by the UN Inter-Agency Group for Child Mortality Estimation.

[10] WHO (World Health Organization) (2018) Maternal Mortality. http://www.who.int/news-room/fact-sheets/detail/maternal-mortality

[11] Ajeani, J., Ayiasi, R.M., Tetui, M., Ekirapa-Kiracho, E., Namazzi, G., Kananura, R.M., Kiwanuka, S.N. and Beyeza-Kashesya, J. (2017) A Cascade Model of Mentorship for Frontline Health Workers in Rural Health Facilities in Eastern Uganda: Processes, Achievements and Lessons. Global Health Action, 10, Article ID: 1345497.

[12] Ministry of Medical Services (MMS) and Ministry of Public Health and Sanitation (MOPHS) (2013) Accelerating Attainment of Health Goals: The Kenya Health Sector Strategic and Investment Plan (KHSSP): July 2013-June 2017. Ministry of Medical Services (MMS) and Ministry of Public Health and Sanitation (MOPHS), Nairobi.

[13] Ministry of Health (2018) Kenya Health Sector Strategic and Investment Plan, Transforming Health System: Achieving Universal Health Coverage by 2022.

https://www.health.go.ke/wp-content/uploads/2020/11/Kenya-Health-Sector-Strate gic-Plan-2018-231.pdf

[14] Grimshaw, J. (2000) Experimental and Quasi-Experimental Designs for Evaluating Guideline Implementation Strategies. Family Practice, 17, 11S-16S. https://doi.org/10.1093/fampra/17.suppl 1.S11

[15] Measure Evaluation PIMA (2017) Monitoring and Evaluation Toolkit for the Scale-Up of Emergency Obstetric and Newborn Care (EmONC) in Kenya. https://www.measureevaluation.org/resources/publications/tr-17-150

[16] Walensky, R.P., Kim, Y., Chang, Y., Porneala, B.C., Bristol, M.N., Armstrong, K. and Campbell, E.G. (2018) The Impact of Active Mentorship: Results from a Survey of Faculty in the Department of Medicine at Massachusetts General Hospital. BMC Medical Education, 18, 1-8. https://doi.org/10.1186/s12909-018-1191-5

[17] Wozniak, T.M., Miller, E., Williams, K.J. and Pickering, A. (2020) Championing Women Working in Health across Regional and Rural Australia-A New Dual-Mentorship Model. BMC Medical Education, 20, Article No. 29.

https://doi.org/10.1186/s12909-020-02219-w

[18] Eby, L.T., Allen, T.D., Evans, S.C., Ng, T. and Dubois, D. (2008) Does Mentoring Matter? A Multidisciplinary Meta-Analysis Comparing Mentored and Non-Mentored Individuals. Journal of Vocational Behavior, 72, 254-267. https://doi.org/10.1016/j.jvb.2007.04.005

[19] Balmer, J.T. (2012) Transforming Continuing Education across the Health Profes- 
sions. Journal of Continuing Education in Nursing, 43, 340-341. https://doi.org/10.3928/00220124-20120725-02

[20] Ameh, C.A., Mdegela, M., White, S. and van den Broek, N. (2019) The Effectiveness of Training in Emergency Obstetric Care: A Systematic literature Review. Health Policy and Planning, 34, 257-270. https://doi.org/10.1093/heapol/czz028

[21] Stefaniak, M. and Dmoch-Gajzlerska, E. (2020) Mentoring in the Clinical Training of Midwifery Students-A Focus Study of the Experiences and Opinions of Midwifery Students at the Medical University of Warsaw Participating in a Mentoring Program. BMC Medical Education, 20, Article No. 394.

https://doi.org/10.1186/s12909-020-02324-w

[22] Fransen, A., van de Ven, J., Merién, A., de Wit-Zuurendonk, L., Houterman, S. Mol, B. and Oei, S. (2012) Effect of Obstetric Team Training on Team Performance and Medical Technical Skills: A Randomised Controlled Trial. BJOG: An International Journal of Obstetrics \& Gynaecology, 119, 1387-1393.

https://doi.org/10.1111/j.1471-0528.2012.03436.x

[23] Abraham, T.H., Stewart, G.L. and Solimeo, S.L. (2021) The Importance of Soft Skills Development in a Hard Data World: Learning from Interviews with Healthcare Leaders. BMC Medical Education, 21, Article No. 147.

https://doi.org/10.1186/s12909-021-02567-1

[24] Cancedda, C., Farmer, P.E., Kerry, V., Nuthulaganti, T., Scott, K.W., Goosby, E. and Binagwaho, A. (2015) Maximizing the Impact of Training Initiatives for Health Professionals in Low-Income Countries: Frameworks, Challenges, and Best Practices. PLoS Medicine, 12, Article ID: e1001840. https://doi.org/10.1371/journal.pmed.1001840

[25] Block, L.M., Claffey, C., Korow, M.K. and McCaffrey, R. (2005) The Value of Mentorship with Nursing Organizations. Nursing Forum, 40, 134-140. https://doi.org/10.1111/j.1744-6198.2005.00026.x

[26] Cust, F. (2018) Increasing Confidence of First-Year Student Nurses with Peer Mentoring. Nursing Times, 114, 51-53.

[27] Gayrama-Borines, Z. and Zabriskie, D. (2018) Implementation of Mentorship Program in the Emergency Department.

https://www.doctorsofnursingpractice.org/wp-content/uploads/project form/compl ete $250218114436 . \mathrm{pdf}$ 